\title{
EXAMINING THE EFFECTIVENESS OF COMMUNITY-BASED LEARNING IN PROMOTING STUDENT "CIVIC-MINDEDNESS" AT UNIVERSITIES: A CASE STUDY IN EGYPT ${ }^{1}$
}

\author{
Nagwa Megahed a, Ted Purinton ${ }^{b}$, Amani El-Shimi ${ }^{c}$, Jennifer Skaggs d, Mona Amer e \\ aAin Shams University, Egypt \\ bcde The American University in Cairo, Egypt \\ Corresponding email: nmegahed@aucegypt.edu
}

\begin{abstract}
This study focuses on Community-Based Learning (CBL, also known as service learning), which is recognized as a transformative pedagogy that promotes student engagement and develops civic responsibilities. In turn, it improves educational outcomes and job opportunities. Focusing on a private university in Egypt as a case study, this research assesses the extent to which a) CBL promotes student development as civic-minded graduates (CMG) and b) provides educational alternatives that enable students to gain the necessary knowledge, skills and dispositions for engaged community advancement. This was achieved after adapting and employing quantitative tools, developed by the Center for Service \& Learning at Indiana University-Purdue University Indianapolis (IUPUI) upon their permission. A total of 114 students completed the CMG surveys in two rounds of data collection. The findings of this study reveal the level of students' civicmindedness at the selected university and show how various student experiences on campus contribute to the student CMG overall average score.
\end{abstract}

Keywords: Community-based Learning, Civic Education, University Students, Egypt.

\section{Introduction}

The importance of civil society to compensate for the highly centralized, high-stakes examoriented educational system in a developing country such as Egypt is undeniable. The problem of Egyptian university students graduating with academic knowledge that does not intersect with real-world issues or employment needs deserves attention, especially that the majority of students in the Private University (PU), examined in this case study are Egyptian nationals, who are accustomed to a high-school educational culture that may not prioritize civic engagement. In addition, disparity between the rich/poor in Egypt is a pressing social issue. The authors address these issues by examining the extent to which CBL has been effective in fostering its intended learning outcomes for students, especially the extent to which it promotes student development as civic-minded graduates. The main research question of this study is: To what extent has CBL been effective in fostering its intended learning outcomes for students as "civic-minded graduates"?

\footnotetext{
${ }^{1}$ This study has been funded by The American University in Cairo, the Provost's competitive research grant titled "Boundary Crossing and Community Integrated Research Initiative (BCCI)", 2016 - 2017
} 
To answer the research question, we firstly discuss community-based learning as a transformative pedagogy, then; articulate its common meaning to provide the theoretical grounding of this study. This is followed by the research methods and findings.

\section{Community-Based Learning: A Transformative Pedagogy}

Educators argue that community-based learning (CBL), also known as service learning, promotes student engagement and develops civic responsibilities, which in turn improves educational outcomes and job opportunities. CBL enhances the competencies of problem analysis and problem-solving, as it immerses learners within real communities, rife with social troubles and complications (Davidson, 2002).Thus, CBL is regarded as a transformative pedagogy, one that creates engaged citizens and "engaged university campuses" (Hamner, Wilder, \& Avery, 2002). Research has identified potential areas of growth and development among students who participate in community-based learning courses. These areas are related to the broad notion of citizenship as students become civic-minded graduates who are socially responsible. Examples of areas of growth include (Celio, Durlak, \& Dymnicki, 2011):

- academic outcomes: enhanced ability to apply learning material to the "real world," ability to tie theory with research or applications, enhanced critical thinking, problem analysis, creative thinking;

- personal outcomes: increased self-esteem, self-efficacy, and confidence;

- social outcomes: improved teamwork and group work skills, better communication skills, enhanced leadership ability and multicultural sensitivity;

- moral outcomes: better understanding of social problems affecting their community, enhanced sense of social responsibility and civic values, and increased commitment to future service and civic engagement; and

- career development outcomes: reflection on or confirmation of career choices and gaining career-specific skills.

Universities typically denote "civic education of students as an explicit goal" (Bringle and Steinberg 2010, p. 2), where "civic engagement can occur through teaching, research, or service that is done in and with the community and includes a variety of activities" (Bringle and Hatcher 2009, p. 38-39). Civic engagement is seen as an active process where the campus mission supports the use and cultivation of the skills and knowledge of members of the campus to improve the quality of life in the community (Bringle and Hatcher 2007, p. 80). There is an increasing recognition amongst governments, international development agencies, NGOs and young people of the importance of youth civic engagement. "Civic engagement is one of the key components for positive youth development and the successful transition to adulthood. It allows young people to practice and exercise citizenship, develop life skills and enhance their employability and learning outcomes. Youth development programs can significantly impact communities, increasing social capital, decreasing violence, providing key social services and meeting overall community development needs" (Hutter, 2008, p.7).

Community-based learning could be described as a form of pedagogy that fosters civic engagement. It is defined as "a teaching method, which enriches learning by engaging students in meaningful services to their schools and communities" (Hutter, 2008, p. 12). Young people apply academic skills to solve world issues and link established learning objectives with community needs. Schools, universities, NGOs, youth clubs and student associations could organize the activities (Hutter, 2008). Community-based / service learning is a pedagogy that combines academic study with community service is becoming increasingly popular throughout the world. It aspires to achieving both personal and academic development for students and civic goals of responsibility towards the community and social justice. 
Community-based learning is believed to be grounded on the experiential learning theory, a pedagogical philosophy links theory to practice in an attempt to enrich the learning experience. Through community-based learning "concrete experience, reflective observation, conceptualization, and active experimentation" all become components of the classroom (Khabanyane \& Alexander, 2013, p. 105).

\section{Common Understanding of the Meaning of CBL}

The PU defines CBL as "a teaching methodology that advances course learning goals through service to a partner community." The PU Course Catalogue states in the description of CBL courses that "students reflect on the changes within themselves, within the partners they've worked with, and within the community at large to assess the impact of civic engagement and responsibility of oneself, others, and the world." It is this integral aspect of CBL that distinguishes it from other forms of community engagements (i.e., volunteerism) which is the exchange and reciprocal relation that takes place between the community and the institution and its students. This is reflected in the key principles of CBL, which are:

- alignment of service to the academic course learning outcomes

- participatory empowerment of partners

- reciprocity of gain

- active meta-cognitive reflection on the process of learning

It is worth mentioning that when interviewing faculty members, they were asked if they agree or disagree with the PU definition of CBL. Although faculty members in general agreed with the PU's definition, they provided suggestions that would further clarify the meaning of CBL. For example, a faculty member suggested specifying the meaning of what a community could be, as explained it could be both the PU community and the Egyptian community at large. Other faculty members felt that the definition lacks the emphasis on the experiential learning aspect of CBL and the larger effects this teaching strategy has on students.

Community-based learning and service learning are used interchangeably. The IUPUI chooses to use the term service learning, highlighting its focus on practicum and internship. Service learning is seen to be more encompassing as it "intentionally identifies the civic growth of students fostered through structured reflection and meaningful experiences with community organizations" (Steinberg, Hatcher, \& Bringle, 2011, p.19). Through credit-bearing courses, students "participate in an organized service activity that meets identified community needs [and] reflect on the service activity in such a way as to gain further understanding of course content, a broader appreciation of the discipline, and an enhanced sense of personal values and civic responsibility" (Teaching, Research, Evaluation, and Assessment, 2017).

\section{Research Methods}

This research employs a quantitative approach to assess CBL experience as related to student civic-mindedness. The authors adapted and customized quantitative tools, developed by IUPUI, to assess the extent to which CBL promotes the development of students as civic-minded graduates. Quantitative data were collected using the adapted Civic-Minded Graduate (CMG) survey for students. A total of 114 students completed the CMG surveys in two rounds of data collection. In the next section, we further explain the process of data collection and analysis, followed by the research findings.

\subsection{Community-Based Learning and Measuring Students' Civic-Mindedness}

In the Egyptian context, a comprehensive study on the effectiveness of community-based learning and its impact on students' overall civic mindedness were missing, whether in private or public universities. Have students increased their understanding on social issues and community needs throughout their university years? Does the university experience inspire 
students to rethink their career path to one of improving society and contributing back to the local community? To what extent does the university education increase students' levels of selfawareness and civic identity?

In response to these questions, this study utilized the civic-minded graduate assessment tools which were developed by the Center for Service \& Learning at Indiana University-Purdue University Indianapolis (IUPUI). Official permission was obtained for the institutional use of these tools at PU. For the purposes of this study, the same IUPUI definition for a "civic-minded graduate" was used, which is: a person who has completed a course of study (e.g. bachelor's degree) and has the capacity and desire to work with others to achieve the "common good." "Civic Mindedness" refers to a person's inclination or disposition to be knowledgeable of and involved in the community, and to have a commitment to act upon a sense of a responsibility as a member of that community".

The study conducted at IUPUI consisted of Study One $(n=70)$, Study Two $(n=86)$, and Study Three ( $n=606)$. Study One only consisted of the quantitative CMG tool, which was both positively and negatively worded. In Study Two, the survey used only positively worded items, and the Marlowe-Crowne Social Desirability Scale was also measured. Study Three measured the CMG Scale (a quantitative measure) as well as the CMG Interview (an oral qualitative measure). The survey that was modified for this research was the positively worded tool used in IUPUI's second and third study. The two round of field studies that we conducted at the PU consisted of Pilot-Study $(n=70)$ and Round Two Study $(n=73)$.

\section{Process}

\subsection{Pilot the Adapted Survey of Civic-Minded Graduate (CMG)}

The first step was conducting a pilot study of the IUPUI modified survey. The purpose was to establish preliminary evidence of the reliability and validity of the CMG scale within the PU context. The research team identified and customized tools for institutional assessment of CBL outcomes at PU. Given that most assessment tools were developed in the United States, this study reviewed, modified and validated the tools for cultural-sensitivity, so that they can be utilized for assessment, future research and institutional planning. The research team was responsible for the revision, customization and adaptation of qualitative and quantitative tools for assessing students as civic-minded graduates.

The quantitative tool adopted by IUPUI consists of three sections. The original six questions in Section I asked students to respond to a few demographic items (e.g. gender, age, major, service-based financial aid, etc.) Upon revisiting this section, the research team added two additional questions, including one of nationality and high school certificate. The purpose of including these two questions was to test whether different high school educational statuses (public, American, French, German high schools) or cultural backgrounds had an effect on students' overall civic-mindedness.

Section II consisted of seven questions about students' frequency of participation in community activities such as campus service events, advocacy, and student club involvement. The scale used by IUPUI used for this section ranged from 1 to 5, 1 being None/Never and 5 being Nearly Every Week, with designated frequencies in between. For this study, we added a sixth anchor, "More than Once a Week" in order to capture students who are very involved in the activities listed. Along with adding a few more items to this section in order to uncover different aspects of the student experience (for example, community service through faith-based organizations), the research team also modified existing items to make them more culturally and socially appropriate within the Egyptian context. As the IUPUI originally states, "the domains of the CMG are all rooted in an American understanding of civic learning" (Steinberg, Hatcher, 
\&Bringle, 2011, p.28). Therefore, different societal dynamics and cultural realities are bound to shape the conceptualization of civic-mindedness in different ways. For example, while the original survey asked respondents about the frequency of their participation in political debates and political campaigns, our research team altered the wording due to the sensitivity towards political activism in Egypt. For this reason, "political civic engagement" and "volunteering for political campaigns" was chosen as a close variant of the original item.

The CMG Scale constituted Section III of the survey, which included a 30-items self-report measure. These 30 items fall under IUPUI's specific domains clustered by knowledge, skills, dispositions, and behavioral intentions. Minor changes were made to the wording of a few items. One of the major modifications to this section was including two additional questions, which were variations of two existing items in the original survey, making the total number of items 32. These two items were significantly modified because they were viewed as not entirely applicable within the Egyptian culture. The customized questions were added to the original 30 questions in the pilot survey to see if there is variation in answers amongst the original and modified questions.

Students in this section were asked to rate the extent to which they agreed or disagreed with the 30 statements with a 6-point response format. While the same rating scale was used (1-Strongly Disagree, 6-Strongly Agree), the research team explicitly specified that anchors 2 - 5 represent ( 2 =Once Each School Year, 3 = Once or Twice Each Semester, $4=$ About Once a Month, $5=$ Nearly Every Week). This was done to give students a clearer definition of the anchor so they can more accurately respond to each item.

In the IUPUI study, two pilot studies were conducted. Social Desirability was not measured in the former, but was in the latter. The pilot study conducted at PU included the 13-item MarloweCrowne Social Desirability Scale. Because civic-mindedness is likely to be a socially desirable trait, the Social Desirability Scale was added at the very end of the survey in order to test whether the CMG scale used contained a social desirability response bias, although the Marlowe-Crowne Social Desirability Scale was not included in IUPUI's first pilot study.

\subsubsection{Data Collection}

The pilot study was conducted on the 8th and 9th of May, 2016, at the PU's campus. Surveys were handed out in various parts of the campus, with the hopes of getting an even distribution of gender, college class, and department. A "convenience sampling" method was used. A total of 70 respondents took part in the pilot-study, 33 males and 37 females. There were 18 Freshmen, 11 Sophomores, 16 Juniors, 16 Seniors, four Graduate students, one Non-Degree, and four "Other"all of whom were Alumni-students. Once the data was collected, the information was inputted in SPSS.

\subsubsection{Findings}

The participants $(n=70)$ were all PU students or alumni. The Cronbach's alpha of the CMG scale was 0.950, which indicates a high internal reliability in the survey. Out of the 70 participants, only 54 respondents were computed in the internal reliability test, since the software excludes any respondent who had missing data.

In IUPUI's Study Two (n=86), Cronbach's alpha was 0.96 in both the fall and spring semesters, indicating a similar high internal reliability (Steinberg, Hatcher, \& Bringle, 2011, p.25). The similar Cronbach's alpha score suggests that the modifications in the survey conducted at PU did not negatively affect the internal reliability of the survey.

The mean CMG Scale Overall Average Score was 4.0815. IUPUI did not publicly report a CMG Scale Overall Average Score, however, data was found on a similar study conducted at Southwest Minnesota State University (SMSU), whose mean was 3.73. A one sample T-test was 
conducted to measure the significance of the difference between the means. The difference in the means was statistically significant at $\mathrm{p}<0.01$.

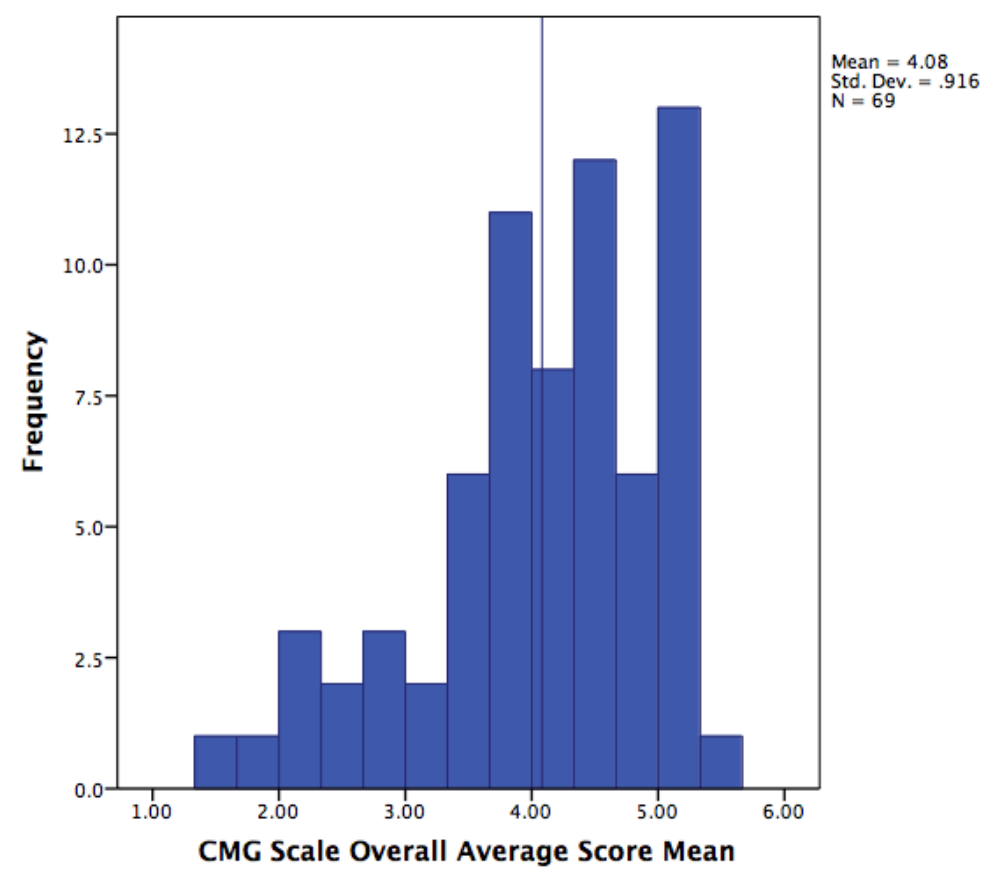

Figure 1. Civic-Minded Graduate Scale Overall Average Score Mean of the Pilot-Survey

In this pilot study conducted at PU, the correlation between the number of CBL courses taken by students $(n=62)$ and the CMG Scale Overall Average Score was statistically insignificant $\mathrm{p}>0.05$. IUPUI's pilot study had a statistically significant positive correlation of 0.380 . The data was also divided into all of the subscales (Knowledge, Disposition, Skills, Behaviors) and the correlation between number of CBL courses taken by students and the subscale average was measured. All the subscales rendered statistically insignificant correlations.

This pilot study also aimed at measuring the correlation between the Crowne-Marlowe Social Desirability scale and the CMG Scale Overall Average Score. The correlation was statistically insignificant at 0.220 , at p>0.05. This measure was tested during IUPUI's second pilot study and the correlation was also found to be statistically insignificant. Therefore, it can be said that there is no correlation between social desirability and the CMG scale answers.

In this pilot study, the goals of testing the validity and reliability of the CMG tool were achieved. The research team established preliminary evidence that the CMG tool is internally reliable even after modifications were made to reflect PU's cultural and social context. The next step was to administer the study to upper year students, while further modifying the concerns students addressed in the pilot-study. Namely, the survey should be reduced in order to appeal to a wider range of willing participants.

\subsection{Administer the Adapted Survey of Civic-Minded Graduate (Round Two)}

\subsubsection{Process}

The purpose of the Round Two of quantitative data collection was to develop the survey and deliver it to a large sample size of upper year, Junior and Senior, students. The research team further developed the survey, modifying it further to address the concerns that arose from the 
pilot study. The main change in the survey was the deletion of questions in order to address the complaints of a large proportion of sample population in the pilot study. Respondents often complained about the length, while others simply refused to take the survey due to its length. Therefore, the number of questions in Sections I and II was reduced from 45 to 34. The CMG scale in Round Two was reduced to a 23-point scale. Few questions were slightly modified to clarify the meaning. Furthermore, the 13-item Marlowe-Crowne Social Desirability Scale was deleted since it was determined in the pilot study that there was no correlation between social desirability and the CMG Scale.

The Round Two study took place on Wednesday the $8^{\text {th }}$ and Monday the $13^{\text {th }}$ of February, 2017 at the PU. A "convenience sampling" method was employed. A total of 76 students participated in Round Two. However, two of those students incorrectly identified themselves as upper year students, and turned out to be sophomores. Of the 74 students, there are 37 Juniors and 37 Seniors, 31 of which are males and 43 females.

\subsubsection{Findings}

The participants $(n=73)$ were all PU juniors and seniors. The Cronbach's alpha of the CMG scale was 0.908, which indicates a high internal reliability in the CMG scale. Sixty-six of the 73 respondents were computed in the internal reliability test, since the software excludes any respondent who had missing data. The pilot study conducted at PU $(n=53)$ had an internal reliability of 0.950. In IUPUI's Study Three $(n=606)$, Cronbach's alpha was 0.96 (Steinberg, Hatcher, \& Bringle, 2011, p.25). The Cronbach's alpha score in IUPUI's Study Three and PU's pilot study indicates that the deletion and modification of question in this round of data collection slightly affected the internal reliability.

The mean of the CMG Scale Overall Average Score $(n=73)$ was 4.0801 (minimum=1.96; maximum 5.70; mean: 4.0801; SD: 0.80994). This is equal to the mean of the pilot study conducted at PU. The mean of the CMG Scale Overall Average Score was once again compared to the mean CMG Scale Overall Average Score of Southwest Minnesota State University (SMSU), whose mean was 3.73 . The difference in means was still statistically significant at $\mathrm{p}<0.001$.

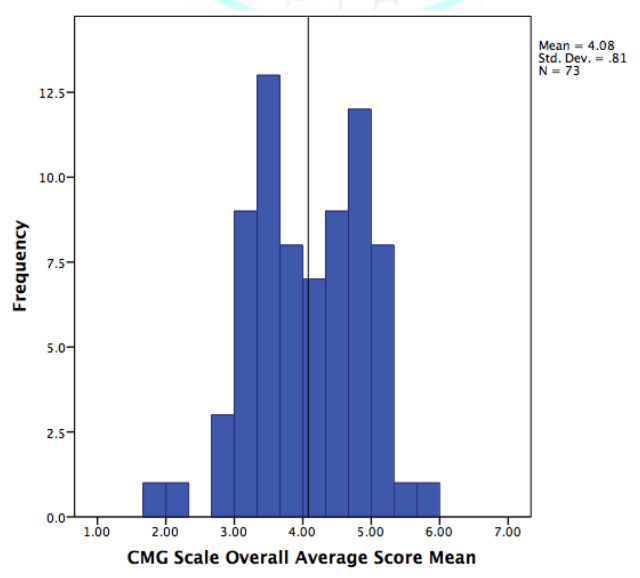

Figure 2. Civic-Minded Graduate Scale Overall Average Score Mean of the Administered Survey

When assessing the difference of means between juniors (4.0606) and seniors (4.0992), the difference is statistically insignificant. This indicates that the difference between the two college classes is not significant. For the correlation between the number of CBL courses taken by students (only 66 students reported the number of CBL courses they took) and the CMG Scale 
Overall Average Score, the results were statistically insignificant $(\mathrm{p}=0.305)$. IUPUI's Study Three $(n=595)$ had a statistically significant result with a positive correlation of 0.340 . It is important to note, however, that a large number of students reported taking no CBL courses.

Next, each of the "Experience" questions was treated as their own indicator of the extent to which students participated in civic activities. Since questions in the Experience section asked about involvement in independent, past, and campus based community activities, the correlation between each individual question and the CMG Scale Overall Average Score was measured. Only two questions rendered statistically significant results. The first one is the "Community involvement through a campus club or organization or other activities such as SU elections, involvement with student body government, etc." question and CMG Overall Scale Average Score; there was a small positive correlation of 0.274 at $p<0.05$. The second question with statistically significant results is the "Community service with faith-based organizations (mosque or church-related service activities)" question. There was a small negative correlation of -0.233 where $\mathrm{p}=0.05$.

The data was also divided into all of the subscales (Knowledge, Disposition, Skills, Behaviors). The means of each subscale was calculated.

Table 1: Civic-Minded Graduates' Overall Average Score and Subscales Means

\begin{tabular}{|l|c|c|c|l|l|}
\hline \multicolumn{7}{|c|}{ CMG Overall Average Score and Subscales Means } \\
\hline & $\mathrm{N}$ & $\begin{array}{l}\text { Mini } \\
\text { mum }\end{array}$ & $\begin{array}{l}\text { Maximu } \\
\text { m }\end{array}$ & Mean & $\begin{array}{l}\text { Std. } \\
\text { Deviation }\end{array}$ \\
\hline $\begin{array}{l}\text { CMG Overall } \\
\text { Average Score }\end{array}$ & 73 & 1.96 & 5.70 & 4.0801 & .80994 \\
\hline Knowledge & 73 & 1.57 & 5.57 & 3.8490 & .95647 \\
\hline Skills & 73 & 1.88 & 5.75 & 4.3337 & .81685 \\
\hline Dispositions & 73 & 1.33 & 5.86 & 4.1024 & .91967 \\
\hline
\end{tabular}

The correlation between number of CBL courses taken by students and the subscale average was measured. Similar to the pilot study done at PU, all the subscales were statistically insignificant. However, since the survey modification left only one behavioral intentions question left the relationship between the "behavioral intentions" subscale and CMG average score couldn't be measured. When assessing the respondents' answers to the questions in section III of the survey, divided by the three of the subscales (Knowledge, Skills, and Dispositions). All the questions asked how their PU experiences/knowledge gained/education has developed students in regards to the knowledge gained, skills attained and dispositions acquired.

In the knowledge questions, the percentage of respondents who agreed to the statements (from Strongly Agree to Somewhat Agree) was between 49.3 and 77.5. The question with the lowest percentage of agreement amongst the entire CMG scale was the one pertaining to how good PU prepared students to write their views on community issues in public forums.

The largest proportion of agreements to the questions fell under the skills related question. The respondents agreed between 64.4 to 82 percent of the time. This section also has the question with the highest percentage of agreement. The largest proportion of student consent came in the question that asked how well PU prepared students to listen and understand others' perspective 
on controversial issues. The Disposition, as presented in figure 5 , questions had responses that agreed to varying degrees between 59.7 to 79.5 percent. However, what is generally found among the student responses in all questions is that except for one questions, approximately 60 to 82 percent of the responses to the questions were between Strongly Agree and Somewhat Agree.

\section{Conclusion}

To summarize the above quantitative study, the piloting of the civic-mindedness survey reaffirmed the validity and application of the IUPUI modified survey in the Egyptian/PU context. The administration of the survey expanded the scope by delivering it to upper year students in hopes of seeing whether or not correlations lie between civic mindedness and number of CBL courses taken. However, many students reported to taking no CBL courses (the reasons of which cannot be determined by the data collected in the surveys). The relationship between CBL courses taken and civic mindedness is statistically insignificant.

Nevertheless, the mean CMG overall average score (4.08) was significantly higher than that of SMSU (3.72). Although the sample size in study two may seem small, the findings of the DAIR study support that PU students have a positive response to how their educational experiences contributed to various forms of civic-mindedness. When assessing how various student experiences contribute to the CMG overall average score, the only positive correlation found was between the "Community involvement through a campus club or organization or other activities such as SU elections, involvement with student body government, etc." activity and CMG. The "Community service with faith-based organizations (mosque or church-related service activities)" rendered a statistically significant negative correlation. 


\section{References}

i. $\quad$ Bringle, R. \& Hatcher, J., 2007. Civic Engagement and Service Learning: Implications for Higher Education in America and South Africa. Education as Change, 11(3), pp. 79-89.

ii. Bringle, R. \& Hatcher, J., 2009. Innovative practices in service-learning and curriculum engagement. New Directions for Higher Education, 2009(147), pp. 37-46.

iii. Bringle, R. \& Steinberg, K., 2010. Educating for Informed Community Involvement.. American Journal of Community Psychology, 46(3-4), pp. 428-441.

iv. Celio, I., Durlak, J. \& Dymnicki, A., 2011. A Meta-analysis of the Impact of Service-Learning on students. Journal of Experiential Education, 34(2).

v. Davidson \& Richard, A., 2002. Community-Based Education and Problem Solving: The Community Health Scholars Program at the University of Florida. Teaching and Learning in Medicine: An International Journal, 14(3), pp. 178-181.

vi. Gray, J., 1999. Combining Service and Learning in Higher Education: Evaluation of the Learn and Serve America, Higher Education Program, 1999. Santa Monica, CA: RAND Education.

vii. Hamner, J., Wilder, B. \& Avery, G., 2002. Community-based service learning in the engaged university. Nursing Outlook, 50(2), pp. 67-71.

viii. $\quad$ Hutter, K., 2008. Young People's Civic Engagement in East Asia and the Pacific: A regional study conducted by Innovations in Civic Participation. Bangkok: UNICEF, EAPRO.

ix. $\quad$ IUPUI, 2015. Civic-minded graduate. Center for Service and Learning. [Online] Available at: http://csl.iupui.edu/teaching-research/opportunities/civic-learning/graduate.shtml

x. IUPUI, n.d. Teaching, Research, Evaluation, and Assessment.. [Online] Available at: http://csl.iupui.edu/teaching-research/opportunities/courses.shtml [Accessed 11 June 2017].

xi. Khabanyane, M. \& Alexander, G., 2013. Service learning as a response to community/school engagement: Towards a pedagogy of engagement. Perspectives in Education, 31(2), pp. 102-113.

xii. $\quad$ Steinburg, K., Hatcher, J. \& Bringle, R., 2011. Civic-Minded Graduate: A North Star. Michigan Journal of Community Service Learning, 18(1), pp. 19-33. 